\title{
Holocaust education 25 years on: Challenges, issues, opportunities
}

\author{
Andy Pearce \& Arthur Chapman
}

Centre for Holocaust Education, Curriculum, Pedagogy \& Assessment, UCL Institute of Education, London, United Kingdom

Postal address: Centre for Holocaust Education, UCL Institute of Education, Level 1, 23-29 Emerald Street, London, WC1N 3QS.

Email: a.pearce@ucl.ac.uk $\underline{\text { arthur.chapman@ucl.ac.uk }}$

\section{Contents}

Contexts: Teaching and learning about the Holocaust in England

Parameters of the Special Issue 6

Overarching themes and central issues 8

Conclusion 13 


\section{Holocaust education 25 years on: Challenges, issues, opportunities}

This essay provides an introductory overview to the articles contained within this Special Issue. It suggests that the recent passage of 25 years since the Holocaust first appeared as a statutory subject in the English National Curriculum represents a key moment to "mark time": that is, to make the first moves in constructing an anthropology of Holocaust education in the postmodern epoch. It is argued the need for this is pressing; not least because landmark research by the UCL Centre for Holocaust Education has highlighted serious issues in relation to students' knowledge and understanding of the Holocaust. This national research has international significance, and is used in this Special Issue as the starting point for reflections from both educators and historians in England and beyond.

Keywords: Holocaust education; teaching and learning; National Curriculum; Holocaust memory.

Marking time, as the anthropologist Paul Rabinow has observed, has multiple modalities and "several clusters of meaning". There is, for example, that which "forms around pauses" - what Rabinow calls "a treading between goal-orientated actions", commonly "reflective" in tenor and pivoting on questions such as "where should I go next? And how should I get there?" Then, there is a modality with more a more "performative" set of meanings: "a keeping of time" akin to the function of an orchestral conductor, or "an ordering of temporal sequence" one might deem as the domain of historians. Finally, Rabinow suggests there is an amalgam of the two: an enterprise where the "anthropologist of the contemporary" incorporates the reflective and the performative, "gather[ing] them together, while adding an active practice of inquiry of a distinctive sort". ${ }^{1}$

This Special Issue on Holocaust education is very much infused with the spirit of Rabinow's anthropology of the contemporary. As its departure point the Issue takes the recent $25^{\text {th }}$ anniversary of the implementation of the National Curriculum for school 
history in England - a development which back in 1991 marked the beginning of statutory teaching about the Holocaust in state-maintained schools, and in the process distinguished England from most other European countries at that time. Of course as much as marking anniversaries is a reflective and performative exercise, it is also one that can reinforce erroneous ideas that history can be neatly periodised; moreover, in their modern calibration, anniversaries are often tuned in ways which perpetuate progressive understandings of temporality. Both presumptions are clearly problematic, and in many respects the story of Holocaust education in England 25 years on illustrates this. Teaching and learning about the subject did not suddenly begin in 1991, just as these practices have not inevitably followed a clear, upward trajectory.

Even so, the decision to introduce mandatory Holocaust education in English schools a quarter of a century ago was an immensely significant moment, not lost on contemporaries who had worked long and hard on the ground to advance teaching and learning over the previous decade. ${ }^{2}$ At our present-day juncture, we find ourselves at a particularly appropriate and resonant moment to take stock, critically review and contemplate the distance travelled and the developments which have occurred. The Holocaust is not just a "pervasive presence in British culture and society"33 but one which, year on year, seems to acquire but greater ubiquity. This process is not without complications, just as the forms this process has taken have given rise to serious - and legitimate - concerns.

\section{Contexts: Teaching and learning about the Holocaust in England}

Embarking upon an "active inquiry" in the vein of Rabinow is as much urgent as pertinent in light of the wider contexts in which teaching and learning about the Holocaust in English schools is taking place. Some of these relate to education and the educational system at large: noteworthy here are attempts to reform education in 
England through the transformation of state schools into academies. The academisation of the English system has been in train for some years, but has accelerated dramatically over the last five years. With these institutions "free" to choose their own curriculum, the very notion of a singular, National Curriculum which the majority of schoolchildren will experience is no longer assured, thereby raising the possibility that not all students will necessarily learn about the Holocaust during their formal schooling. Our instinct quite understandably and rightly - is to be deeply concerned by this, but it actually places primacy upon giving due consideration as to just why we feel all young people should learn about the Holocaust. What is it about this history we regard so essential? Why do we regard it as an indispensable component of a child's education?

Related to these questions are others regarding how and when teaching should occur. Internationally, the past decade has brought an increasing trend towards teaching the Holocaust to an ever-younger age group. In England, a growing number of schools who are preoccupied with the importance of public examination results have moved to "collapse" the curriculum for 11-14 year-olds where the Holocaust has been traditionally housed, to create more space for students to prepare for examinations at the age of 16. The result is that the Holocaust is being taught to a larger number of 11-12 year-olds than before, whilst separate movements have seen the Holocaust being increasingly included in primary school curricula. Indeed, research indicates that $28.5 \%$ of Year 7 students (11-12 year-olds) now enter the secondary system having already studied the Holocaust within the earlier tier of the education system. ${ }^{4}$

The conscious decision by some schools to teach the Holocaust to younger cohorts of students in secondary schools is, in many cases then, explicable in terms of the preoccupation many schools now have with securing "good" public examination results for students aged 16 years-old. This prioritisation is understandable, if no less 
unpalatable: in the grand scheme of things, a school will acquire scant reward for ensuring its students know and understand the Holocaust; of far greater import for its very livelihood is securing high examination grades - especially in key subjects like English, Maths, and Science.

Schools and their politics alone cannot account for all of the changes that have occurred in Holocaust education over recent decades. It is crucial to equally recognise the influence of extra-curricular, non-scholastic influences, more often than not located found in wider culture. The indication that the Holocaust is being increasingly taught to primary schoolchildren is illustrative here. Given that there is no stipulation within the National Curriculum for this to take place, it is legitimate (and pressing) to ask why this has occurred; just why do teachers and primary schools freely choose to teach the Holocaust to their students? What is their reasoning, their rationale?

Part of the answer lies in how the principle and possibility of introducing younger students to the Holocaust has been popularised by cultural phenomena such as films and novels - The Boy in the Striped Pyjamas being a case in point. Major motion pictures and popular literary works have periodically functioned to pique interest in the Holocaust, but in the case of John Boyne's book and its associated film, few have lent themselves explicitly for use with and by young children. At the same time, some nongovernmental organisations have furthered this trend by promoting teaching the Holocaust to young children, and creating materials for this purpose. ${ }^{5}$ For teachers working in the primary sector - many of whom are not trained historians - these are powerful and symbolic moves which, coming from organisations seen to as authoritative, is taken to legitimise practice. Yet if the advancement of Holocaust education among primary age children is very much in vogue, it is also a trend that remains contentious and not underpinned by empirical research. 
All of these structural shifts within the education system carry wide-ranging implications for teaching and learning, for they raise fundamental issues around pedagogical approach and curriculum design. Such matters are, of course, not exclusive to England, but the English case study is particularly salient given the longer-term context and condition of Holocaust education and remembrance in this country. Seen from one perspective, the state of these enterprises in England would seem exemplary: formal and informal programmes for teaching the Holocaust have existed for a generation or more, while the last years of the twentieth century and first years of the twenty first, saw the United Kingdom dramatically elevate itself to be among a group of countries with strong political and institutional commitment to memorialisation and commemoration. This trajectory has only been furthered in recent years by the creation in 2014 of the UK Holocaust Memorial Foundation (UKHMF) - the administrative body established to implement the recommendations of the Holocaust Commission set up by the former Prime Minister, David Cameron. Supported by a cross-party commitment of $£ 50,000,000$ of public money, the UKHMF is overseeing the construction of a new national memorial and accompanying Learning Centre, likely to be sited adjacent to the Palace of Westminster. Outwardly, at least, Holocaust education and remembrance in the United Kingdom generally, and in England specifically, may thus appear to be in rude health.

\section{Parameters of the Special Issue}

Closer inspection suggests a more complicated and conflicted picture. Central to misen-scène must now be added new ground-breaking research into what students know and understand about the Holocaust. Conducted by the UCL Centre for Holocaust Education, this research draws on quantitative and qualitative data from over 9,500 students aged 11-18 years old and presents an incredibly detailed portrait of young 
people's substantive knowledge, conceptual understanding, learning experiences and attitudes towards Holocaust education. Nowhere else in the world has a study of this scale and magnitude been conducted - either into teaching and learning about the Holocaust, or indeed any historical subject. Moreover, this research complements earlier investigation by the Centre into teaching practices, meaning we can now have at our disposal unprecedented empirical insights into how the Holocaust is being taught and learned in English secondary schools.

Coming at the same time as the 25th anniversary of the Holocaust in the English National Curriculum, this research underpin this Special Issue and provides it with a lodestar towards which all of the essays are positioned. However, it is not merely the recent 25th anniversary of the English National Curriculum that makes it an especially important time to reflect on these discoveries. 2016 also marked a quarter century since the final collapse of the USSR, the cessation of Cold War and the dissolution of the post-war settlement of Europe: all developments that reconfigured the research, narrative and interpretive contexts of the Holocaust in significant and enduring ways. ${ }^{6}$ In recognition of these transnational and transcultural dimensions, this Special Issue also seeks to provide a forum for international voices to reflect on the Anglo-Saxon experience, and consider the factors which have shaped it in light of developments in other contexts.

So as to realise these aims, the essays within this Issue are organised into three clusters. The first of these is "Holocaust education in England", containing four essays (Pearce, Pettigrew, Foster and Karayianni, Chapman and Hale) authored by researchers from the UCL Centre for Holocaust Education. Together these essays unpack, explore and discuss the state of Holocaust education in England, and draw on the rich data we now have about teaching practice and students' learning. Whilst all of these essays are 
acutely aware of how education cannot be divorced from its socio-cultural milieu, this sphere is more directly broached by the second cluster of writings - "Reflections on the British context". The two essays housed in this section (Lawson and Kushner), reflect on the research of the UCL's Centre and position it within the broader realms of public history and the British imagination. The final cluster of essays - "International Perspectives" - contains three contributions from colleagues in the United States, Austria, and Germany (Dwork, Kühberger, von Borries). By approaching the UCL's research from their specific national contexts and professional background, these contributors work to consider what transnational significance and transcultural relevance the story of Holocaust education in England and the United Kingdom may have.

\section{Overarching themes and central issues}

Across the spectrum of essays contained within this Special Issue are a number of recurrent challenges and overarching issues. One of these is a question of purpose: why, exactly, is teaching and learning about the Holocaust understood and regarded to be inherently desirable, even necessary? What are the very fundamentals of Holocaust education in terms of its raison d'être, its aims and its objectives?

In his essay "The Holocaust in the National Curriculum after 25 Years", Andy Pearce adopts a cultural history approach and constructs a historical overview of how the Holocaust has been positioned in school curricula in England since 1991. Pearce forcefully argues that a failure to address the issue of rationale has stalked the history of the National Curriculum, and has in turn reflected systemic flaws and shortcomings within the nation's historical consciousness of the Holocaust more broadly. The result, he suggests, is that the confusion and ambiguity one finds in education is mirrored in 
wider Holocaust culture - one which, he advocates, is "characterised by confusion, illogicality, and at times absurdity."

Pearce's discussion of rationale is augmented by Alice Pettigrew's contribution "Why teach and Learn about the Holocaust?" In this synthesis of UCL's two major research projects Pettigrew interrogates the outlooks and attitudes that teachers and learners in England have towards Holocaust education in general, and its aims and purposes in particular. She suggests these mind-sets have at least as much (if not more) influence than political directives like national curricula in shaping the course teaching and learning takes in schools. Moreover, Pettigrew also advances that the idea of "powerful knowledge" - what constitutes it, and the uses it can be put to - is one warranting further consideration in relation to what is to be taught, what is to be learned, and for what ends.

In opening up discussion of epistemology, Pettigrew gestures to matters at the heart of teaching and learning about the Holocaust: just what is it that students should know about this history? How does knowledge relate to understanding? What stratagems can we employ to measure and gauge what students know and understand? The latter of these questions is taken up by Arthur Chapman and Rebecca Hale in their essay "Understanding what young people know". Reflecting on their experiences of developing methods and methodologies for various research projects, Chapman and Hale exemplify effective means of exploring students' knowledge and understanding and powerfully argue for the need to account for progression in students learning. Taking an approach which seeks to marry theory with practice, Chapman and Hale draw on students' descriptions of "the Holocaust" to illustrate the need to recognise, acknowledge, and develop young people's conceptual frameworks as much as their substantive historical knowledge. 
Given the shortcomings and shortfalls revealed by the UCL research, one might quite reasonably wonder what "knowledge" and "understanding" students are presently getting and from where. There is no singular, uniform answer, of course, but in their article "Representing the Holocaust in English History Textbooks, 1991-2015" Stuart Foster and Eleni Karayianni provide intriguing insights. In a digital age where the Internet is King, Foster and Karayianni argue school textbooks remain highly influential and considerably popular resources in classrooms; accordingly, the findings of their examination of 21 texts from the past 25 years offers much food for thought. As much as these materials have "helped to improve students' knowledge, conceptual understanding, and historical consciousness", Foster and Karayianni demonstrate textbooks have been consistently blighted by "key failings" that correlate with the UCL's research into students' knowledge and understanding.

In seeking to address these shortcomings, Foster and Karayianni forward five recommendations, among which is a need for textbook producers to be far "more aware of, and responsive to, emerging historical scholarship." The salience of this call is thrown into sharp relief by Tom Lawson's cogent essay "Britain's Promise to Forget”, which approaches the UCL research through the lens of historiographical advances in recent decades. Throughout his article Lawson underscores how, on numerous levels, what is revealed about student's knowledge and understanding speaks of a "yawning chasm between the academy and the classroom". Yet of even greater concern to Lawson is what this suggests "about the rhetoric of surrounding the purpose of Holocaust education and memorialisation in Britain today.” Like Pearce, Lawson shares scepticism for the so-called "lessons" of the Holocaust, seeing them and the misunderstandings they bring to be "because rather than despite the prevailing noise" 
around the Holocaust. The result, he argues, is we are more actively engaged in forgetting than remembering.

Lawson's incisive critique of how the Holocaust has become "one of the myths that we live by" finds multiple echoes in Tony Kushner's survey "The Holocaust in the British Imagination”. Here, Kushner trains a telling light on the political forces that have forged the particular contours of our contemporary Holocaust culture. By honing in on key moments in the post-war history of Holocaust memory in the United Kingdom, he presents a kaleidoscope of instances in the "official sphere" that reveal how cultural tendencies interface with the condition of young people's knowledge and understanding. Kushner's message of change going hand in glove with continuities mirrors points made by Pearce, while his interrogation of the Prime Minister's Holocaust Commission marries with the tenets of Lawson's analysis. But through his close examination of emergent "silences" Kushner suggests impulses within the political realm to accent a self-congratulatory narrative of the Holocaust "takes scholarship and memory work back at least until 1961”. Even more bluntly, Kushner intimates that much of what now passes as memory work in this country (as seen most recently in the Holocaust Commission's report Britain's Promise to Remember) is little more than "memory comfort" - a conclusion carrying much potency in light of what is now known about students' knowledge and understanding.

The issue of Holocaust "lessons" is taken on by various scholars in this Special Issue and is something that since the turn of the millennium has simultaneously gained increasing traction and been subjected to growing critique. Whilst popular among politicians, many educators, and holding considerable cultural currency, the notion of "lessons" has spurred a rising number of robust critiques from scholars and educationalists in recent years. 
The prospect of transcending what she calls "simplistic 'lessons from the Holocaust" is one which Deborah Dwork welcomes in her article "A Critical Assessment of a Landmark Study". For Dwork, the idea functions as shorthand for the many and multiple claims that have been made about the benefits of Holocaust education in recent decades - claims which, she suggests, now need to be re-evaluated in light of the UCL research into students' knowledge and understanding. Whilst careful to note the many positives to emerge from these findings, including encouraging indications about students' attitudes and the impact of certain aspects of Holocaust education, Dwork maintains "if the point of studying the past is to help us understand the present, students' knowledge about the Holocaust is insufficient to help them negotiate the world in which they live". Pulling no punches Dwork is stark in her assessment that "this is a pivotal moment" - not just for Holocaust education in England and the United Kingdom, but by implication internationally as well.

Christoph Kühberger's article "Teaching the Holocaust and National Socialism in Austria" follows Dwork's lead of reflecting on the condition of students' knowledge and understanding in his own national context in light of the UCL research. Presenting a wide-ranging analysis that explores the politics of memory and history in Austria in the post-war period and beyond, Kühberger examines trends in the ways in which the memory of National Socialism and the Holocaust has been managed in Austrian society. These are juxtaposed to developments in Austrian education, with Kühberger drawing on recent empirical work in Salzburg and on findings from research into Austrian history textbooks. By comparing this data with the UCL findings, Kühberger identifies continuities and contrasts, before outlining nine challenges currently facing the treatment of National Socialism and the Holocaust in history education. 
In the concluding essay of this Special Issue Bodo von Borries adopts a macro approach to the current state of Holocaust education internationally. "Learning and Teaching about the Shoah - Retrospect and Prospect" builds on what was originally a concluding address to the International Holocaust Remembrance Alliance (IHRA)'s Lucerne conference in February 2016, and sees von Borries reflects less on the landscape of research and more on the nature and challenges of the IHRA project, taking into account contemporary German perspectives and on pedagogic challenges associated with learning about the Holocaust. In a very personal and contemplative article, von Borries considers the meanings of learning from and learning about the Holocaust in the light of contemporary challenges to human rights.

\section{Conclusion}

It is of course impossible for any Special Issue to capture the multidimensional nature of Holocaust education in the contemporary world, or to cover the plethora of issues related to it. However, by bringing together these experts at this time and utilising the empirical data now available to us, we believe the essays in this Special Issue will open up dialogue about the challenges, issues and opportunities that now exist within and around Holocaust education. As much as these essays therefore mark the passage of time, then, they are also intended to mark the beginning - not the end - of conversations about where we could, and should, "go next" and how best to get there. All too often such questions are eschewed for convenience, or passed over for fear of the difficult discussions they entail. As these essays show, now is not the time to shy away from these urgent and pressing issues.

\section{Notes:}


${ }^{1}$ Rabinow, Marking Time, vii.

${ }^{2}$ Interestingly enough, for those pioneers the National Curriculum was never understood as a magic wand; rather, as important and unexpected as it was, the move was understood to be part of a broader set of initiatives which were necessary to overcome "suspicion" and "misunderstanding" about "the Holocaust" in the United Kingdom. Indeed, it is worth recalling that this very journal was formally launched as The British Journal of Holocaust Education just a few months after the National Curriculum for history came into effect, having originally been conceived as a means of transmitting "information and academic material", of providing in the words of inaugural editor John Fox "a forum for informed debate and discussion on a wide range of historical, educational, philosophical, religious, and sociological issues concerned with the teaching and research of the Holocaust in the United Kingdom.” See Fox, Teaching the Holocaust, 63; Yad Vashem Committee of the United Kingdom, Minutes, September 25, 1990, ACC/3121/C/23/1/2. Fox, "Editor's Foreword”, 1.

${ }^{3}$ Pearce, Holocaust consciousness.

${ }^{4}$ In England, compulsory schooling is divided into a 'primary' (5-11 years-old) and a 'secondary' phase (11-16 years old). Many students remain in school or college between the ages of 16 and 19 but this is not compulsory.

${ }^{5}$ See for instance educational resources and programmes developed by the Holocaust Memorial Day Trust, the Holocaust Centre, the Holocaust Educational Trust, and the Anne Frank Trust UK.

${ }^{6}$ Judt, Postwar, 303-831.

\section{References}

Foster, S., et al., (2015). What do students know and understand about the Holocaust? Evidence from English secondary schools London: Centre for Holocaust Education.

Judt, T. (2006) Postwar: A history of Europe since 1945. London: Vintage. 
Pearce, A. (2014). Holocaust consciousness in contemporary Britain. New York \& London: Routledge.

Pettigrew, A., et al., (2009) Teaching About the Holocaust in English Secondary

Schools: An empirical study of national trends, perspectives and practice. London: Holocaust Education Development Programme.

Rabinow, P. (2007) Marking Time: On the Anthropology of the Contemporary. New Jersey, Princeton University Press. 